\title{
What will it take to stop the tobacco epidemic?
}

\author{
Navjoyt Ladher head of education
}

The BMJ

It's almost 70 years since Richard Doll and A Bradford Hill published their landmark paper in The BMJ linking smoking to lung cancer (doi:10.1136/bmj.2.4682.739). In the intervening years we've learnt more about the range of lethal harms to health from tobacco and about the industry's predatory practices. We also know more about the measures that successfully reduce and prevent smoking: taxation, smoke free laws, marketing restrictions, and smoking cessation services.

Yet tobacco remains a leading cause of death and illness around the world, killing around eight million people every year, WHO estimates (www.who.int/news-room/fact-sheets/detail/tobacco). In the UK, while smoking rates are declining, hospital admissions related to smoking are rising (http://bit.ly/2IPEQRO), and there is a worrying trend of cuts to smoking cessation services (doi:10.1136/bmj.k3649).

WHO's Framework Convention on Tobacco Control is a high profile answer to the tobacco epidemic. A major international treaty with 181 signatories covering over $90 \%$ of the world's population, the framework sets out measures to reduce harmful tobacco consumption, lower smoking rates among children, and counteract the industry's lobbying and promotional activities.

This week a research paper by Steven Hoffman and colleagues analyses changes in smoking rates since the legally binding treaty was adopted in 2003 (doi:10.1136/bmj.12287). Using data from 71 countries, they found no significant change in the rate at which global cigarette consumption decreased after adoption of the framework. In a linked editorial Linda Bauld says that this is down to slow implementation of the framework, particularly in low and middle income countries that have limited capacity to withstand industry lobbying against tobacco control measures (doi:10.1136/bmj.14161).

Two signatories to the WHO treaty are China and Japan, both state owners of tobacco companies. Flynn Murphy and Gabriel Crossley describe how China and Japan's investments in tobacco, and the revenues and jobs they provide, conflict with their public health responsibilities (doi:10.1136/bmj.12328). But when it comes to tobacco control, state ownership may be preferable to private ownership, say Joanna Cohen and Kelley Lee (doi:10.1136/bmj.14056), as past experience shows that tobacco industry privatisation leads to an increase in smoking. The bigger issue is not about who owns tobacco companies but how strictly the industry is regulated. Regardless of ownership, Cohen and Lee say, we need comprehensive regulation that puts public health ahead of economic interests. Stopping the tobacco epidemic will require nothing less. 